\title{
Contemporary treatment trends for upper urinary tract stones in a total population analysis in Germany from 2006 to 2019: will shock wave lithotripsy become extinct?
}

\author{
Roman Herout $^{1}$ (I) Martin Baunacke ${ }^{1}$. Christer Groeben ${ }^{1} \cdot$ Cem Aksoy $^{1} \cdot$ Björn Volkmer ${ }^{2} \cdot$ Marcel Schmidt $^{3}$. \\ Nicole Eisenmenger ${ }^{4} \cdot$ Rainer Koch ${ }^{1}$. Sven Oehlschläger ${ }^{1} \cdot$ Christian Thomas $^{1}$. Johannes Huber ${ }^{1}$
}

Received: 11 June 2021 / Accepted: 20 August 2021 / Published online: 28 August 2021

(c) The Author(s) 2021

\begin{abstract}
Purpose To describe the change in upper urinary tract stone management in Germany over a 14-year period. Methods Using remote data processing we analyzed the nationwide German billing data from 2006 to 2019. To analyze the clinics' case numbers and regional trends, we used the reimbursement.INFO tool based on standardized quality reports of all German hospitals. To also cover shock wave lithotripsy (SWL) as an outpatient procedure, we analyzed the research database of the Institute for Applied Health Research with a representative anonymous sample of 4 million insured persons. Results The number of inpatient interventional therapies for upper tract urolithiasis in Germany increased from 70,099 cases in 2006 to 94,815 cases in 2019 (trend $p<0.0001$ ). In-hospital SWL declined from 41,687 cases in 2006 to 10,724 cases in 2019 (decline of 74\%; trend $p<0.0001$ ). The percentage of SWL as an outpatient procedure increased between 2013 and 2018 from 36 to $46 \%$ of all performed SWL, while total SWL case numbers declined. Contrarily, the number of ureteroscopies increased from 32,203 cases in 2006 to 78,125 cases in 2019 (increase of 143\%; trend $p<0.0001$ ). The number of percutaneous nephrolithotomy also increased from 1673 cases in 2006 to 8937 in 2019 (increase of 434\%; trend $p<0.0001$ ). Conclusion We observed an increase in interventional therapy for upper tract urolithiasis in Germany with a dramatic shift from SWL to endoscopic/percutaneous treatment. These changes may be attributed to enormous technological advances of the endoscopic armamentarium and to reimbursement issues.
\end{abstract}

Keywords Urolithiasis · Percutaneous nephrolithotomy · Ureterorenoscopy · Extracorporeal shock wave lithotripsy $\cdot$ Health services research

\section{Introduction}

Urolithiasis is a worldwide health issue with millions of people affected by symptomatic calculi in the upper urinary tract every year. The most recent data on incidence and prevalence in Germany were published for the year 2001 with $1.5 \%$ and $4.8 \%$, respectively [1]. Factors such

Roman Herout

roman.herout@uniklinikum-dresden.de

1 Department of Urology, University Hospital Carl Gustav Carus, TU Dresden, Fetscherstraße 74, 01307 Dresden, Germany

2 Department of Urology, Klinikum Kassel, Kassel, Germany

3 Coloplast GmbH, Hamburg, Germany

4 Reimbursement Institute, Hürth, Germany as stone location, calculus size, anatomy of the collecting system, patient comorbidities and preference as well as surgeon preference have impact on the selection of the therapeutic modality [2]. Due to these various aspects that need to be considered, modern stone therapy needs to be individually tailored to the patient. Guidelines on urolithiasis, such as the European (EAU), the American (AUA) and the German (DGU), help in the decision-making process. However, for most urinary stones several options are available and need to be discussed with the patient [2-4]. Technological advances with miniaturization of instruments, the ability to fragment larger stones with modern lasers and the broad availability of flexible ureteroscopes have caused a shift from shock wave lithotripsy (SWL) to endoscopic or percutaneous approaches in the treatment of urolithiasis worldwide [5]. The numbers of SWL as an inpatient procedure in German hospitals were declining 
from 2005 to 2013 [6]. This trend has also been shown in a recently published nationwide survey in which 199 urology departments in Germany were asked about their treatment preference for urolithiasis. In summary, $87 \%$ of urological departments stated that less than $30 \%$ of all urinary stones are treated with SWL. $43 \%$ of all departments stated that $51-70 \%$ of all stone therapy is done via ureterorenoscopy (URS) and further $43 \%$ of all departments stated that more than $70 \%$ of all cases are managed via URS [7].

The aim of this study was to evaluate treatment trends for upper urinary tract stones in Germany over a study period of 14 years.

\section{Materials and methods}

We followed the "REporting of studies Conducted using Observational Routinely collected health Data" (RECORD) statement [8].

\section{Nationwide billing data in Germany (diagnosis-related groups database)}

A total population analysis of the nationwide billing data in Germany from 2006 to 2019 was performed. In 2004 the international diagnosis related groups (DRG) had been implemented in the German health care system, thus regulating the reimbursement of inpatient treatment. The DRG are comprised of the diagnosis coded via the ICD10 (International Statistical Classification of Diseases and Related Health Problems) code and an OPS code (German adaption of the International Classification of Procedures in Medicine) for the performed intervention. Data of each treated case are first transferred to the Institute of Hospital Remuneration and subsequently to the German Federal Statistical Office (Destatis). The nationwide Destatis database contains every reimbursed inpatient case in Germany except for psychiatric, forensic, and military hospitals. We previously described this methodology in more detail $[9$, 10].

For data analysis we combined a specific code for urolithiasis as primary or secondary diagnosis (Table S1) with a specific OPS-code (Table S2). SWL and percutaneous nephrolithotomy (PCNL) have very specific OPS codes, which are exclusively used for urolithiasis. That is not true for ureteroscopy. However, by combining a urolithiasis-specific ICD code with a specific OPS code we were able to identify procedures that were performed for upper tract calculi. Also, in 2010 a specific OPS code for flexible ureteroscopy was introduced, which gave us the opportunity to discriminate between semirigid and flexible ureteroscopy for the years 2010-2019.

\section{InGef research database}

URS and PCNL are not routinely performed in an outpatient setting in Germany. In contrast, SWL is performed as an inpatient or outpatient procedure varying between hospitals and regions within Germany. To also cover SWL as an outpatient procedure, we analyzed the research database of the Institute for Applied Health Research (InGef). For this purpose, we extracted the ratio of inpatient to outpatient SWL for every year from 2013 to 2018 and used this ratio to estimate the number of outpatient SWL treatments per year from the known number of inpatient procedures from the Destatis database. The InGef research database is an anonymized claims database with high external validity, comprising longitudinal data from approximately $6.7 \mathrm{mil}-$ lion persons insured in one of 70 German statutory health insurances [11]. For the purpose of this analysis, the InGef Research Database was condensed to a sample of approximately 4 million insured people which is representative of the German population in terms of age and region [11].

\section{Hospital quality reports}

Hospitals in Germany are obliged to record and report data concerning diagnosis and treatment annually (ICD and OPS codes). We used the analysis tool "reimbursement.INFO" (RI Innovation $\mathrm{GmbH}$, Hürth, Germany) to extract data on hospital procedures for treating upper urinary tract stones for the years 2006 to 2019. For small annual caseloads of 1,2 or 3 cases the exact number was not provided, but instead 1 for data protection reasons. The maps were rendered with the software easymap ${ }^{\odot}$ office (Lutum + Tappert DV-Beratung GmbH, Bonn, Germany).

\section{Data protection and ethics statement}

We performed all actions in accordance with the Declaration of Helsinki in its latest version. Analyzed data were completely anonymized and derived from established databases with rigorous data protection measures. Therefore, an additional ethics statement was not required.

\section{Statistics}

Linear regression for trend analysis and Wald tests were performed with SAS V9.4 (SAS Institute, Cary, NC). 


\section{Results}

Unless otherwise noted, all trends refer to the total study period from 2006 to 2019.

We observed an increasing case number of surgically treated upper tract urinary stones from 70,099 to 94,815 cases (total increase of $35 \%$ or $2 \%$ per year; trend $p<0.0001)$. The number of clinics performing these therapies declined from 512 to 481 (trend $p<0.0001$ ). The mean patient age at intervention was $53 \pm 15.7$ years and $68 \%$ were males. Both, age and the sex ratio did not significantly change over time. The mean LOS for all interventions considerably decreased from $4.7 \pm 4.6$ days to $3.4 \pm 4$ days (trend $p<0.0001$ ). Figure 1 provides an overview of all surgical therapies for upper tract urinary calculi in Germany from 2006 to 2019.

We observed a steady decline in inpatient SWL from 41,687 cases in 411 clinics to 10,724 cases in 325 clinics, i.e. a total decline of $73 \%$ or $10 \%$ per year (trend $p<0.0001$ ). This SWL decline is mirrored by the regional changes displayed in Fig. 2. 77\% of SWL were performed for kidney stones and $23 \%$ for ureteral stones. The mean LOS decreased from $4.4 \pm 4.4$ days to $3.1 \pm 3.2$ days (trend $p<0.0001)$. We observed a shift towards more outpatient procedures with $36 \%$ of all SWL done in an outpatient setting in 2013 versus $46 \%$ in 2018. The estimated number of outpatient SWL cases were 13,122 in 2013, 16,916 in $2014,15,319$ in $2015,14,711$ in $2016,14,918$ in 2017 , and 11,152 in 2018.
The total number of URS for upper tract urolithiasis showed a steady increase from 32,203 cases to 78,125 cases with an average increase of $7 \%$ per year (total increase of $143 \%$; trend $p<0.0001)$. Regional changes for URS (for all indications) are depicted in Figure S1. 495 hospitals in Germany reported stone-related URS in 2006 and 475 hospitals in 2019 (trend $p=0.0009$ ). The mean LOS decreased over time from $5.3 \pm 4.6$ days to $3.1 \pm 3.7$ days (trend $p<0.0001$ ). In 2010, 2785 flexible URS cases were recorded in 146 clinics. In the year 2019, there were 25,541 flexible URS cases performed in 356 clinics (total increase of $817 \%$; trend $p<0.0001)$. On average we observed a $30 \%$ increase in flexible URS per year (shown in figure S2). The mean LOS decreased over time from $4.3 \pm 3.6$ days in 2010 to $3.1 \pm 4.1$ days in $2019(p<0.0001)$. A single-use ureteroscope was coded for 2,775 cases in 2018 and for 4,432 cases in $2019(p<0.0001)$.

The number of PCNL increased from 1673 cases to 8937 cases (average increase of $16 \%$ per year and a total increase of $434 \%$; trend $p<0.0001$ ). PCNL was performed in 282 hospitals in Germany in 2006, and the number steadily increased to 364 clinics in 2019 (trend $p=0.0002$ ). This increase in hospitals that offer PCNL is depicted in figure $\mathrm{S} 3$. The mean LOS declined from $12 \pm 8.2$ days to $6.5 \pm 6.8$ days (trend $p<0.0001$ ).

The number of open procedures for upper tract urolithiasis steadily declined from 553 cases in 237 clinics to 294 cases in 163 clinics, i.e. a total decline of $47 \%$ or $5 \%$ per year (trend $p<0.0001$ ). The mean LOS decreased from

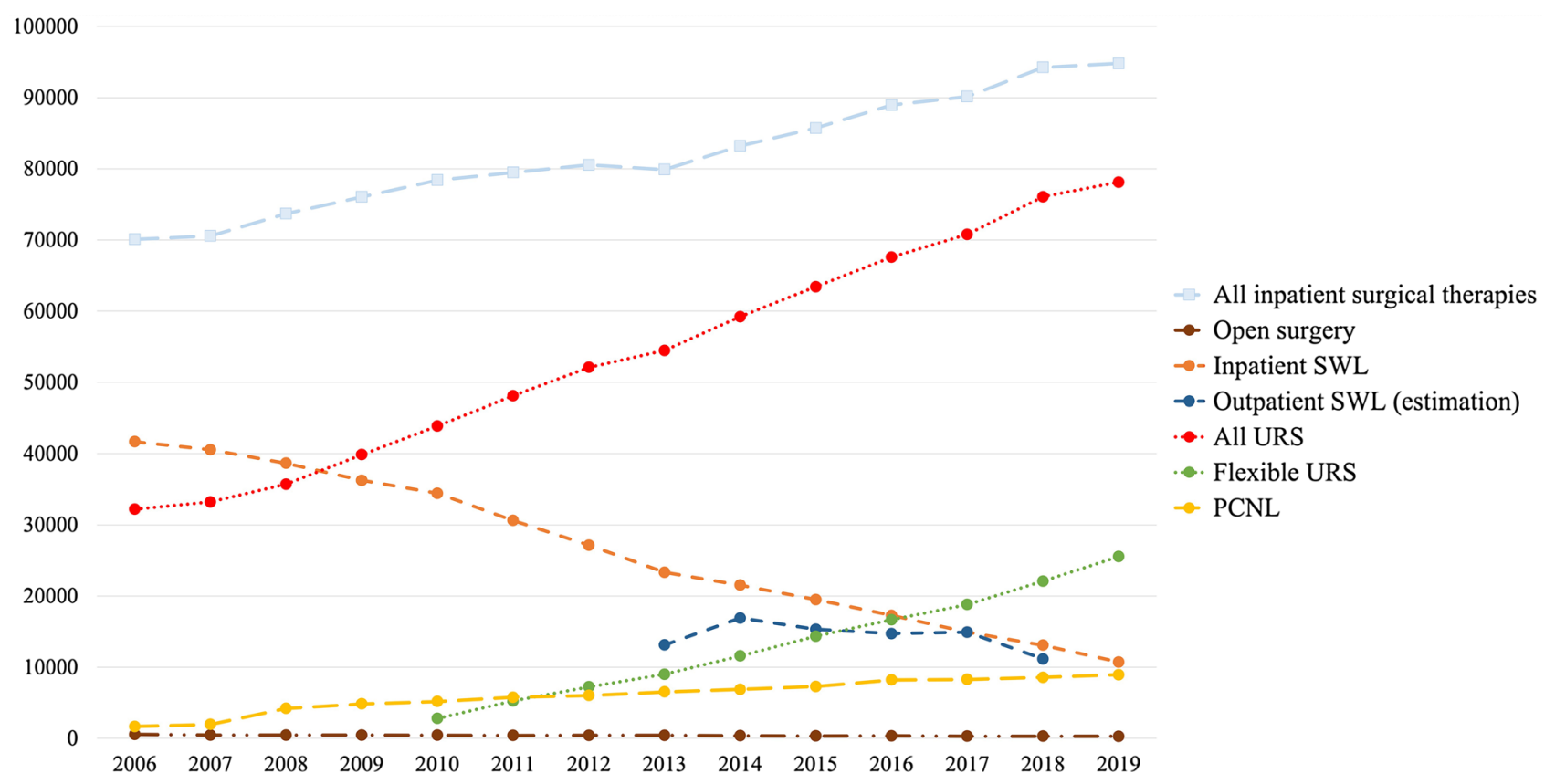

Fig. 1 Surgical therapies for upper tract urinary calculi in Germany from 2006 to 2019 

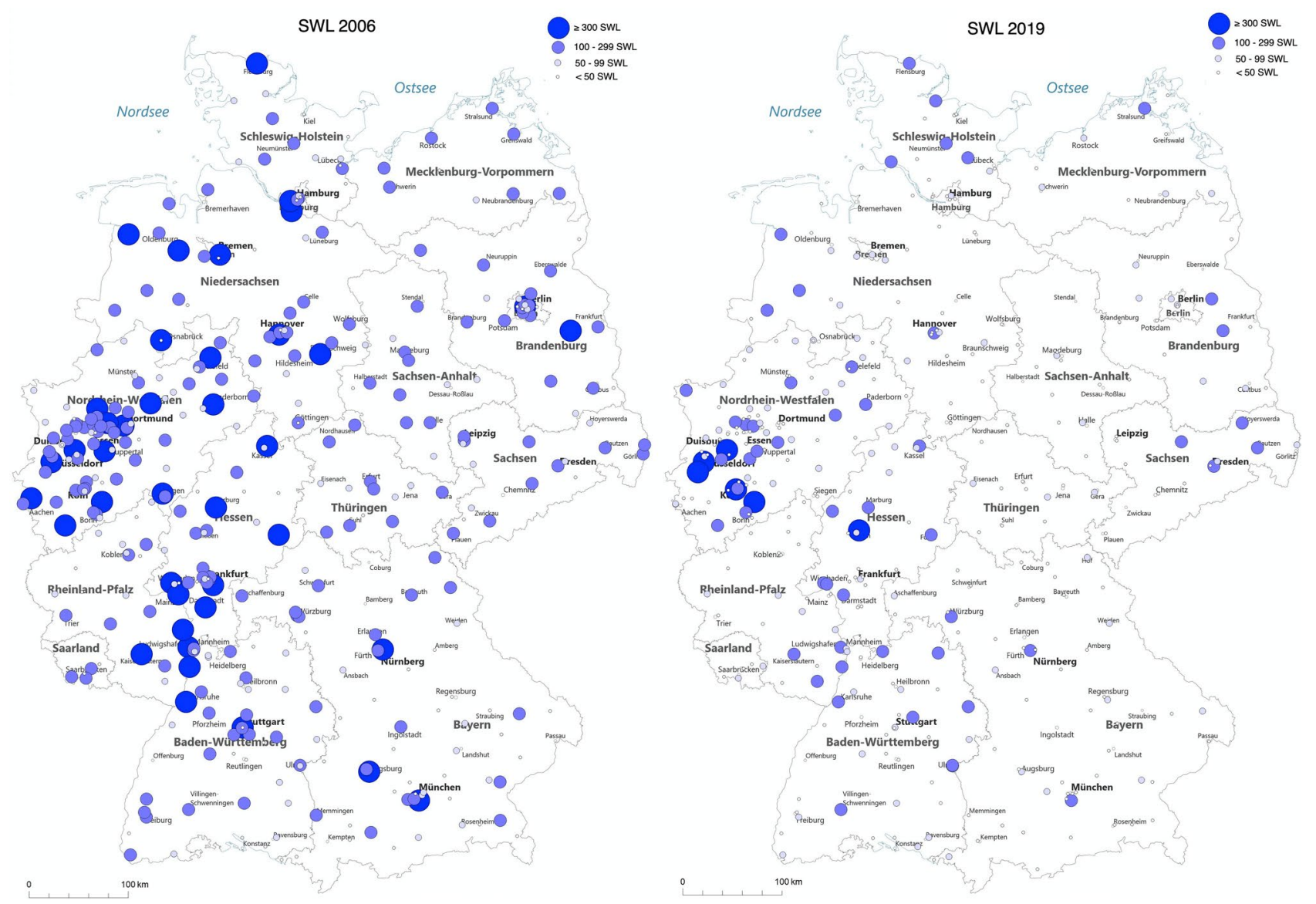

Fig. 2 Regional changes in SWL case numbers in Germany from 2006 to 2019

$16.7 \pm 9.5$ days in 2006 to $11.2 \pm 6.4$ days in 2019 (trend $p<0.0001)$.

\section{Discussion}

We present contemporary German total population data over a study period of 14 years on all surgical interventions for upper urinary tract stones. The total number of inhospital procedures for all upper tract urolithiasis increased from 70,099 cases in 2006 to 94,815 cases in 2019 and we observed a strong trend towards endoscopic or percutaneous procedures. This increase in surgical interventions is most likely attributed to an increased life-time prevalence of urinary tract stones due to a higher prevalence of metabolic disorders in the population (obesity, metabolic syndrome, type 2 diabetes mellitus) and also, due to fact that with the widespread use of computed tomography (CT) more asymptomatic upper tract urinary calculi are being diagnosed [12, 13].

Open stone surgery is rarely performed nowadays: case numbers were low in 2006 and dropped by almost $50 \%$ over the study period. In-hospital SWL numbers were decreasing with 41,687 inpatient SWL in 2006 compared to 10,724 inpatient SWL cases in 2019 (declined by 74\%).

This decline in SWL numbers was not merely caused by a shift from an inpatient to outpatient setting of the procedure, but total SWL case numbers dropped. Nevertheless, assessing SWL as an outpatient procedure in Germany is cumbersome as no single and reliable data source is available. The quality reports that German hospitals are obliged to provide, comprise all inpatient and outpatient SWL that are performed by hospitals. However, they do not account for office-based urologists with SWL machines in their office. There are no published data on how many stationary and mobile SWL machines are used by office-based urologists in Germany, but via addressing the quality reports and the InGef database, we can provide a valid estimate for the total number of outpatient SWL.

We observed a dramatic decline in the utilization of SWL, which seems to be multifactorial: First, indications for the different stone therapies have changed over the years. After its introduction in 1980, SWL was soon adopted worldwide as a minimally invasive treatment option for ureteral and 
kidney stones [14]. However, the advances in endoscopic instruments in the late 1990s and early 2000s, and the introduction of laser fragmentation led to a decline in utilization of SWL. Furthermore, in contrast to the advances in our endoscopic armamentarium, improvements in SWL technique have not been likewise implemented in clinical practice over the last two decades. Recent developments such as enlargement of the focal zone, enlargement of the focus, improvement of efficacy of electrohydraulic shock-wave source, "burst-SWL", and high-frequency shock waves have not yet been addressed by the shrinking lithotripter market [15-20].

Second, there are factors specific for Germany with regards to billing and reimbursement when it comes to SWL. Acceptance of SWL as in-patient treatment by health insurance companies has become very difficult, since it can be performed safely as an outpatient procedure in most patients. However, reimbursement of outpatient SWL is on an average $66 \%$ lower than for inpatient treatments [21]. Therefore, reimbursement issues could possibly represent another driving factor in the change from SWL to endoscopic treatments. Patients that are admitted to the hospital ward for a procedure might as well undergo endoscopic treatment instead of SWL. This is even more so the case, when beforehand a ureteral stent has been established in the emergent state of a symptomatic, blocking ureteral stone. Usually, patients are discharged after a ureteral stent has been placed and the obstruction was relieved. This practice is very common in Germany and only few patients undergo an immediate "in situ" SWL or "emergency SWL" [22, 23].

Last, from our personal experience, more and more patients tend to opt for an efficient and fast stone therapy, favoring URS or PCNL as first choice compared to SWL [24].

As a result of the strong decline in SWL, we observed an increase in endoscopic upper urinary tract stone therapies. Today, modern holmium and thulium lasers can be utilized through flexible instruments and fragment any stone irrespective of its composition. Another cornerstone in modern URS was the introduction of the "dusting"-technique. Likewise, in PCNL progress has been made with miniaturization and improvements in instruments and auxiliary tools like the Holmium laser. All these aspects and the equalization of endoscopic approaches with SWL in the primary treatment of upper tract stones $<10 \mathrm{~mm}$ in national and international guidelines, led to a dramatic increase in the number of endoscopic treatments for upper tract stones composed of the increment in URS (+ 143\%) and PCNL (+ 434\%).

The German DRG reimbursement system is intended to be a "learning system" and every year adjustments are made to keep health costs under control [6]. We assume that this fact led to a downgrade of SWL with regard to reimbursement, in favor of URS and PCNL, hence impeding the acquisition of new SWL machines. We observed a significant reduction in the LOS for patients after URS from 5.3 to 3.1 days, which is one way for hospitals to compensate for the high costs. As of 2019 the LOS was the same for URS and SWL. The relatively long hospital stay for SWL patients can be explained by patients undergoing multiple SWL sessions (every other day in an inpatient setting) and by the fact that SWL is part of a DRG group of surgeries with high invasiveness (including retroperitoneal surgery) and hospitals are facing cuts in remuneration if patients are discharged too early.

With the growing PCNL experience and smaller nephroscopes (mini-PCNL) urologists started to treat smaller kidney stones via PCNL. Recently, more and more experienced centers have implemented tubeless mini-PCNL for small stones, which can result in a faster stone free state for the patient and higher reimbursement. For PCNL we observed the most dramatic decrease in length of hospital stay from 12 to 6.5 days.

Similar trends are reported for England with increasing URS and PCNL cases between 2006 and 2014 [25]. However, in contrast to our data, SWL case numbers remained stable over the study period. Additionally, in England almost $25 \%$ of URS cases were done as day-case URS, whereas same day discharge is a rarity in Germany [25].

Many countries have introduced the diagnosis-related groups (DRG) system since the early 2000s, including England, Finland, France, Germany, Poland, the Netherlands, Sweden, and Switzerland, to increase transparency and to ensure a rational and economic use of resources in the health care systems [26]. Regardless of its achievements, significant improvements and changes to the existing DRG system in Germany must be made, especially outpatient procedures and day-case surgeries should be reinforced. Certainly, the observed trends in upper urinary stone treatment in Germany cannot be extrapolated to other countries; thus efforts shall be made to gather more epidemiological data on stone therapy in various countries and health care systems.

Shared decision making with active participation of the patient in the process is of utmost importance, especially given that, according to the findings of Omar et al. up to $85 \%$ of patients are likely to defer the final decision on upper tract stone therapy to the physician [27]. Consequently, reimbursement must not be a key factor when patients are counselled for choosing their stone therapy.

Our study has several limitations: The given numbers in this work are case numbers and do not represent individual patients. Patients may have had multiple interventions and various combinations of the above-mentioned stone therapies. Furthermore, our data do not give information on comorbidity, calculus size, calculus composition, complications, and retreatment rates. Procedural coding is linked to reimbursement and, therefore, it is possible that specific 
codes with higher reimbursement rates are used more frequently, where applicable. Nevertheless, extracting billing data on upper tract urolithiasis has proven to yield valid results in various other studies [25, 28-30].

\section{Conclusion}

The number of SWL performed in Germany has been steadily declining over the past decade and the worldwide trend towards endoscopic/percutaneous procedures has been confirmed in the German health system. The fate of SWL in upper urinary tract stone management will depend on the implementation of recent technological developements and on finding a suitable framework for remuneration within the German health care system.

Supplementary Information The online version contains supplementary material available at https://doi.org/10.1007/s00345-021-03818-y.

Acknowledgements This project was developed within the framework of the working group "Health Services Research, Quality and Economics" of the DGU e.V.

Author contributions RH: project development, data analysis, manuscript writing. MB: data analysis, manuscript editing. CG: data analysis, manuscript editing. CA: project development, manuscript editing. BV: project development, manuscript editing. MS: data analysis. NE: data analysis. RK: data analysis. SO: data analysis, manuscript editing. CT: project development, manuscript editing. JH: project development, data analysis, manuscript editing.

Funding Open Access funding enabled and organized by Projekt DEAL. Coloplast $\mathrm{GmbH}$ initiated and paid for the data retrieval by the InGef research database and provided the results free of charge as part of a scientific cooperation. Roman Herout is funded by the Deutsche Forschungsgemeinschaft (DFG, German Research Foundation) -HE 8701/1-1.

Availability of data and material All data used in this work are stored centrally at the specific institutes (German Federal Statistical Office - Destatis; "reimbursement.INFO"-RI Innovation GmbH; InGef Research Database).

Code availability Not applicable.

\section{Declarations}

Conflicts of interest Johannes Huber and Martin Baunacke report non-financial support from Coloplast $\mathrm{GmbH}$ during the conduct of the study (see Funding). Mr. Schmidt is employee of Coloplast GmbH. Mrs. Eisenmenger is Founder and Managing Director of RI Innovation $\mathrm{GmbH}$. All other authors declare that they have no conflict of interest.

Ethics approval All procedures performed in studies involving human participants were in accordance with the ethical standards of the institutional and/or national research committee and with the 1964 Helsinki declaration and its later amendments or comparable ethical standards. Ethics approval was not required.
Consent to participate Not applicable.

Consent for publication Not applicable.

Open Access This article is licensed under a Creative Commons Attribution 4.0 International License, which permits use, sharing, adaptation, distribution and reproduction in any medium or format, as long as you give appropriate credit to the original author(s) and the source, provide a link to the Creative Commons licence, and indicate if changes were made. The images or other third party material in this article are included in the article's Creative Commons licence, unless indicated otherwise in a credit line to the material. If material is not included in the article's Creative Commons licence and your intended use is not permitted by statutory regulation or exceeds the permitted use, you will need to obtain permission directly from the copyright holder. To view a copy of this licence, visit http://creativecommons.org/licenses/by/4.0/.

\section{References}

1. Hesse A, Brändle E, Wilbert D et al (2003) Study on the prevalence and incidence of urolithiasis in Germany comparing the years 1979 vs. 2000. Eur Urol 44:709-713. https://doi.org/10. 1016/s0302-2838(03)00415-9

2. Türk C, Petřík A, Sarica K et al (2016) EAU guidelines on interventional treatment for urolithiasis. Eur Urol 69:475-482. https:// doi.org/10.1016/j.eururo.2015.07.041

3. Assimos D, Krambeck A, Miller NL et al (2016) Surgical management of stones: american urological association/endourological society guideline, Part I. J Urol 196:1153-1160. https://doi.org/ 10.1016/j.juro.2016.05.090

4. Seitz C, Bach T, Bader M, et al (2018) S2k-Leitlinie zur Diagnostik, Therapie und Metaphylaxe der Urolithiasis (AWMF Registernummer 043-025). https://www.awmf.org/uploads/tx_szleitlinien/ 043-0251_S2k_Diagnostik_Therapie_Metaphylaxe_Urolithiasis_ 2019-07_1.pdf Accessed 12 July 2021

5. Geraghty RM, Jones P, Somani BK (2017) Worldwide trends of urinary stone disease treatment over the last two decades: a systematic review. J Endourol 31:547-556. https://doi.org/10.1089/ end.2016.0895

6. Bauer J, Kahlmeyer A, Stredele R, Volkmer BG (2014) Inpatient therapy of urinary stones in Germany: development of the G-DRG system. Urologe [A] 53:1764-1771. https://doi.org/10. 1007/s00120-014-3720-0

7. Reicherz A, Sahin R, Häuser L et al (2021) (2021) An empirical study on the operative treatment of symptomatic urolithiasis in Germany. Urol Int 105(3-4):240-246. https://doi.org/10.1159/ 000510589

8. Benchimol EI, Smeeth L, Guttmann A et al (2015) The reporting of studies conducted using observational routinely-collected health data (RECORD) statement. PLoS Med 12:e1001885. https://doi.org/10.1371/journal.pmed.1001885

9. Groeben C, Koch R, Baunacke M et al (2017) High volume is the key for improving in-hospital outcomes after radical prostatectomy: a total population analysis in Germany from 2006 to 2013. World J Urol 35:1045-1053. https://doi.org/10.1007/ s00345-016-1982-4

10. Groeben C, Koch R, Baunacke M et al (2018) Urinary diversion after radical cystectomy for bladder cancer: comparing trends in the US and Germany from 2006 to 2014. Ann Surg Oncol 25:3502-3509. https://doi.org/10.1245/s10434-018-6381-1

11. Andersohn F, Walker J (2016) Characteristics and external validity of the German health risk institute (HRI) database. 
Pharmacoepidemiol Drug Saf 25:106-109. https://doi.org/10. $1002 /$ pds. 3895

12. Abufaraj M, Siyam A, Xu T et al (2021) Association between body fat mass and kidney stones in US adults: analysis of the national health and nutrition examination survey 2011-2018. Eur Urol Focus. https://doi.org/10.1016/j.euf.2021.03.010

13. Rob S, Bryant T, Wilson I, Somani BK (2017) Ultra-low-dose, low-dose, and standard-dose CT of the kidney, ureters, and bladder: is there a difference? Results from a systematic review of the literature. Clin Radiol 72:11-15. https://doi.org/10.1016/j.crad. 2016.10.005

14. Chaussy C, Brendel W, Schmiedt E (1980) Extracorporeally induced destruction of kidney stones by shock waves. Lancet 2:1265-1268. https://doi.org/10.1016/s0140-6736(80)92335-1

15. Rassweiler JJ, Knoll T, Köhrmann K-U et al (2011) Shock wave technology and application: an update. Eur Urol 59:784-796. https://doi.org/10.1016/j.eururo.2011.02.033

16. Rassweiler J, Rieker P, Rassweiler-Seyfried M-C (2020) Extracorporeal shock-wave lithotripsy: is it still valid in the era of robotic endourology? Can it be more efficient? Curr Opin Urol 30:120-129. https://doi.org/10.1097/MOU.0000000000000732

17. Bianchi G, Marega D, Knez R et al (2018) Comparison of an electromagnetic and an electrohydraulic lithotripter: Efficacy, pain and complications. Arch Ital Urol Androl 90:169-171. https://doi. org/10.4081/aiua.2018.3.169

18. Abid N, Ravier E, Promeyrat X et al (2015) Decreased radiation exposure and increased efficacy in extracorporeal lithotripsy using a new ultrasound stone locking system. J Endourol 29:1263-1269. https://doi.org/10.1089/end.2015.0175

19. Bohris C, Roosen A, Dickmann M et al (2012) Monitoring the coupling of the lithotripter therapy head with skin during routine shock wave lithotripsy with a surveillance camera. J Urol 187:157-163. https://doi.org/10.1016/j.juro.2011.09.039

20. Tailly GG, Tailly-Cusse MM (2014) Optical coupling control: an important step toward better shockwave lithotripsy. J Endourol 28:1368-1373. https://doi.org/10.1089/end.2014.0338

21. Durner L, Bach C, El Howairis MEF et al (2016) Current trends in urolithiasis treatment in various european health systems. Urol Int 96:125-131. https://doi.org/10.1159/000441041

22. Arcaniolo D, De Sio M, Rassweiler J et al (2017) Emergent versus delayed lithotripsy for obstructing ureteral stones: a cumulative analysis of comparative studies. Urolithiasis 45:563-572. https:// doi.org/10.1007/s00240-017-0960-7

23. Bucci S, Umari P, Rizzo M et al (2018) Emergency extracorporeal shockwave lithotripsy as opposed to delayed shockwave lithotripsy for the treatment of acute renal colic due to obstructive ureteral stone: a prospective randomized trial. Minerva Urol Nefrol 70:526-533. https://doi.org/10.23736/S0393-2249.18.03084-9

24. Drake T, Grivas N, Dabestani S et al (2017) What are the benefits and harms of ureteroscopy compared with shock-wave lithotripsy in the treatment of upper ureteral stones? a systematic review. Eur Urol 72:772-786. https://doi.org/10.1016/j.eururo.2017.04.016

25. Rukin NJ, Siddiqui ZA, Chedgy ECP, Somani BK (2017) Trends in upper tract stone disease in england: evidence from the hospital episodes statistics database. Urol Int 98:391-396. https://doi.org/ $10.1159 / 000449510$

26. Mihailovic N, Kocic S, Jakovljevic M (2016) Review of diagnosisrelated group-based financing of hospital care. Health Serv Res Manag Epidemiol 3:2333392816647892. https://doi.org/10.1177/ 2333392816647892

27. Omar M, Tarplin S, Brown R et al (2016) Shared decision making: why do patients choose ureteroscopy? Urolithiasis 44:167-172. https://doi.org/10.1007/s00240-015-0806-0

28. Semins MJ, Trock BJ, Matlaga BR (2010) Validity of administrative coding in identifying patients with upper urinary tract calculi. J Urol 184:190-192. https://doi.org/10.1016/j.juro.2010.03.011

29. Marchini GS, Mello MF, Levy R et al (2015) Contemporary trends of inpatient surgical management of stone disease: national analysis in an economic growth scenario. J Endourol 29:956-962. https://doi.org/10.1089/end.2015.0021

30. Lee M-C, Bariol SV (2011) Evolution of stone management in Australia. BJU Int 108(Suppl 2):29-33. https://doi.org/10.1111/j. 1464-410X.2011.10695.x

Publisher's Note Springer Nature remains neutral with regard to jurisdictional claims in published maps and institutional affiliations. 